\title{
Tribomechanical Properties of a Carbon-Based Nanolayer Prepared by Nitrogen Ion Beam Assisted Deposition for Finger Joint Replacements
}

\author{
Tomas Horazdovsky (D) ${ }^{1}$ and Radka Vrbova ${ }^{2}$ \\ ${ }^{1}$ Faculty of Mechanical Engineering, Czech Technical University in Prague, Prague, Czech Republic \\ ${ }^{2}$ Institute of Dental Medicine, General University Hospital in Prague and First Faculty of Medicine, \\ Charles University, Prague, Czech Republic
}

Correspondence should be addressed to Tomas Horazdovsky; tomas.horazdovsky@fs.cvut.cz

Received 25 December 2017; Revised 30 March 2018; Accepted 8 April 2018; Published 20 May 2018

Academic Editor: Ian R. Cooper

Copyright ( 2018 Tomas Horazdovsky and Radka Vrbova. This is an open access article distributed under the Creative Commons Attribution License, which permits unrestricted use, distribution, and reproduction in any medium, provided the original work is properly cited.

\begin{abstract}
This paper presents the tribomechanical test results of Ti6Al4V alloy modified by carbon-based nanolayers with a thickness of $20 \mathrm{~nm}$ and $40 \mathrm{~nm}$, prepared by nitrogen ion beam assisted deposition. The presence of carbon and nitrogen compounds was observed in the modified surface after ion bombardment. Nonstoichiometric $\mathrm{TiN}_{x}$ was mainly detected near the interface nanolayer/titanium substrate and in the substrate itself. Ion bombardment led to an improved surface hardness of $\sim 13 \mathrm{GPa}$ in comparison to unmodified Ti6Al4V titanium alloy $(\sim 5.5 \mathrm{GPa})$ and alloy coated by carbon nanolayer without nitrogen ion assistance $(\sim 7 \mathrm{GPa})$. The decreasing of friction coefficient was achieved from $0.5-0.6$ for untreated Ti6Al4V alloy to 0.1 for treated Ti6Al4V alloy. Wear testing using a joint wear simulator proved that the modified Ti6Al4V alloy has a higher resistance compared to the unmodified Ti6Al4V alloy. The primary local wear fault of the treated surface was observed after 240,000 cycles in comparison to enormous wear on the untreated surface after just 10,000 cycles. Treating the Ti6Al4V load-bearing components of implants with carbon-based nanolayers assisted by nitrogen ions is very promising in terms of extending the lifetime of implants and thereby reduces patient burden.
\end{abstract}

\section{Introduction}

Titanium (Ti) and its alloys are currently the most attractive materials for biomedical applications due to their beneficial biological compatibility and good mechanical properties. They are used mainly for joint replacements such as knee, hip, shoulder, elbow, wrist, and spine or as dental implant materials.

The Ti6Al4V alloy is the most commonly used material in current implantology. It is characterized by good biocompatibility, high tensile strength and corrosion resistance, and relatively low Young's modulus ( $110 \mathrm{GPa})$ compared with currently used surgical metals [1]. Nevertheless, it has a high stiffness compared to human cortical bone ( 20 GPa) $[2,3]$ which can cause stress shielding effect $[4,5]$. Alloying elements, such as $\mathrm{Al}$ and $\mathrm{V}$, are considered nonbeneficial to the human organism $[6,7]$. For these reasons, more favourable titanium alloys (e.g., based on $\mathrm{Nb}, \mathrm{Ta}, \mathrm{Zr}$, and $\mathrm{Cr}$ ) with lower Young's modulus have been developed and optimized [8-10]. Another problem with commonly used Ti6Al4V alloy is its relatively high coefficient of friction $[1,11]$. This relates to the lower wear resistance, which may result in debris release. The released ions can activate the immune system [12], induce a local inflammatory reaction, or damage the bone structure, which in turn leads to long-term health problems or aseptic implant loosening [13-15].

The longevity of the implant in the human body is influenced by the factors mentioned above. However, the tribological properties and surface hardness play the greatest role, especially in big load-bearing joint replacements. Surface treatment, such as nitriding, carburizing, and oxidation, can improve the wear resistance of Ti materials by forming a hard surface layer $[16,17]$. Ti materials coated by a carbonbased nanolayer are very promising for joint's replacements. 
TABLE 1: Chemical composition of Ti6Al4V alloy.

\begin{tabular}{lc}
\hline Element & Content (wt\%) \\
\hline $\mathrm{Al}$ & $5.50-6.75$ \\
$\mathrm{~V}$ & $3.50-4.50$ \\
$\mathrm{Fe}$ & 0.30 \\
$\mathrm{C}$ & 0.10 \\
$\mathrm{O}$ & 0.20 \\
$\mathrm{~N}$ & 0.05 \\
$\mathrm{H}$ & 0.0125 \\
$\mathrm{Ti}$ & Balance \\
\hline
\end{tabular}

These nanolayers are characterized as being biocompatible with excellent low friction properties, high hardness, and good wear resistance in comparison with Ti substrate. Many techniques are used for their deposition, such as chemical vapour deposition (CVD), plasma-enhanced chemical vapour deposition (PECVD), filtered cathode vacuum arc (FCVA), ion beam assisted deposition (IBAD) [18-23], and pulsed laser deposition (PLD) [24-26]. The adhesion of the carbon nanolayer onto the substrate, its microstructure, chemical composition, surface hardness, friction, and internal stress distribution can be improved by the optimization of the deposition conditions and ion bombardment during surface treatment $[22,27-31]$. Nitrogen ion assistance leads to atomic mixing on the coating/substrate interface and to the formation of $\mathrm{TiN}_{x}$ compounds in the modified zone. Newly formed compounds harden the substrate and significantly participate in the tribomechanical property enhancement of the coated material $[32,33]$.

In this respect, the development of surface modifications aimed at the carbon-based materials bombarded with nitrogen ions is very promising for load-bearing applications. The role of this modifications for real applications needs to be examined in more detail.

The purpose of this work is to characterize and test the Ti6Al4V alloy modified by ion beam assisted deposition of carbon-based nanolayer for finger joint replacements. This system is designed to improve the sliding properties of titanium alloy without risk of delamination known in thick diamond like carbon (DLC) coatings.

\section{Materials and Methods}

2.1. Specimens Preparation. The Ti6Al4V alloy containing $\alpha$ $+\beta$ phase was used as a base material for the preparation of test specimens. The chemical composition of this alloy is shown in Table 1 . Specimens in the form of a cylinder $(20 \mathrm{~mm}$ in diameter and $8 \mathrm{~mm}$ in height) were cut from the titanium bar. The surface of each specimen was ground by a series of abrasive papers with grit of $150,320,500,800,1000$, and 2000 and polished with diamond paste of $5 \mu \mathrm{m}$ and $1 \mu \mathrm{m}$ into the mirror like gloss $\left(R_{a}=0.02 \mu \mathrm{m}\right)$ using a Leco machine. The substrates were ultrasonically cleaned in isopropyl alcohol for 20 minutes before the deposition process.

2.2. Deposition Process. The deposition of carbon-based nanolayer was performed by ion beam assisted deposition
(IBAD). The specimen was placed in a holder positioned on a cooled rotary manipulator in a vacuum chamber. The chamber was evacuated and the work pressure was maintained at about $5 \cdot 10^{-3} \mathrm{~Pa}$ during deposition. The carbon nanolayer was deposited by the electron beam evaporation of a carbon target of high purity (99.9\%) with sequential nitrogen ion bombardment. The acceleration voltage was $90 \mathrm{kV}$ and the fluence of the implanted nitrogen ions was $1 \cdot 10^{17} \mathrm{~cm}^{-2}$. The deposition rate was about $0.10 \mathrm{~nm} \cdot \mathrm{s}^{-1}$. Two groups of specimens with two different thicknesses were prepared. Approximate values of $20 \mathrm{~nm}$ (IBAD $20 \mathrm{~nm}$ ) and $40 \mathrm{~nm}$ (IBAD $40 \mathrm{~nm}$ ) have been determined. The control group contained specimens with carbon nanolayer without nitrogen ion bombardment (C $40 \mathrm{~nm}$ ) and unmodified specimens (Ti6Al4V). A quartz thickness monitor located in the apparatus measured the thickness of the carbon-based nanolayer.

2.3. Characterizations of Treated Surface. The chemical composition of titanium surface modified with implanted nitrogen ions was measured by means of Auger electron spectroscopy (AES) in a PHI SAM 545 spectrometer. For excitation, an electron beam of $3 \mathrm{keV}$ and $1 \mu \mathrm{A}$, with a diameter of $40 \mu \mathrm{m}$, was used. Two symmetrically inclined Ar ion beams of $1 \mathrm{keV}$ sputtered the specimens. For carbon, the sputtering rate is estimated to be $0.7 \mathrm{~nm} / \mathrm{min}$.

The phase composition of titanium alloy modified by carbon nanolayer with nitrogen ion assistance was established by the X-ray diffraction (XRD) measurement using a PANalytical X'Pert PRO powder diffractometer. Cobalt radiation with a wavelength of $0.1789 \mathrm{~nm}$ and geometry with the parallel beam with an incident angle of $0.5^{\circ}$ was used.

Qualitative changes of carbon bonding structure after ion implantation were analysed by Raman spectroscopy. The Raman spectra were found using a Renishaw RM1000 Raman microscope with an Ar laser and excitation at $514.5 \mathrm{~nm}$.

The surface hardness of modified specimens (IBAD $20 \mathrm{~nm}$, IBAD $40 \mathrm{~nm}$, and C $40 \mathrm{~nm}$ ) and unmodified specimens $(\mathrm{Ti} 6 \mathrm{Al} 4 \mathrm{~V})$ was measured by the nanoindentation method on a Hysitron TriboIndenter apparatus with a Berkovich diamond tip. Indents with $10 \mu \mathrm{m}$ separation in the matrix $3 \times 4$ were applied on each specimen. The maximum indentation force was $5000 \mu \mathrm{N}$. The partial load-unload function was used to measure the depth profile of the surface hardness. NanoScratch test method was used for a detection of adhesion behaviour of deposited nanolayer. Scratch testing was performed with conospherical diamond tip (angle $60^{\circ}$ tip radius $1 \mu \mathrm{m}$ ). The tip was cleaned with ethanol. The normal forces in scratch testing were continuously increasing from 2 to $3000 \mu \mathrm{N}$. The scratch length was $10 \mu \mathrm{m}$ and the scratching speed was $1 \mu \mathrm{m} / 1.5 \mathrm{~s}$.

The coefficient of friction was determined on a pinon-disc tribometer equipped with a 100Cr6 steel ball of $6 \mathrm{~mm}$ diameter. Modified specimens (IBAD $20 \mathrm{~nm}$ and IBAD $40 \mathrm{~nm}$ ) were compared with the Ti6Al4V reference specimens. The normal load during the test was $2 \mathrm{~N}$ with the velocity of $6 \mathrm{~cm} \cdot \mathrm{s}^{-1}$ and a radius of rotation of $4 \mathrm{~mm}$.

The distribution of contact pressure between the relatively rigid spherical part of the titanium joint and the much more flexible spherical cup made from polyetheretherketone 


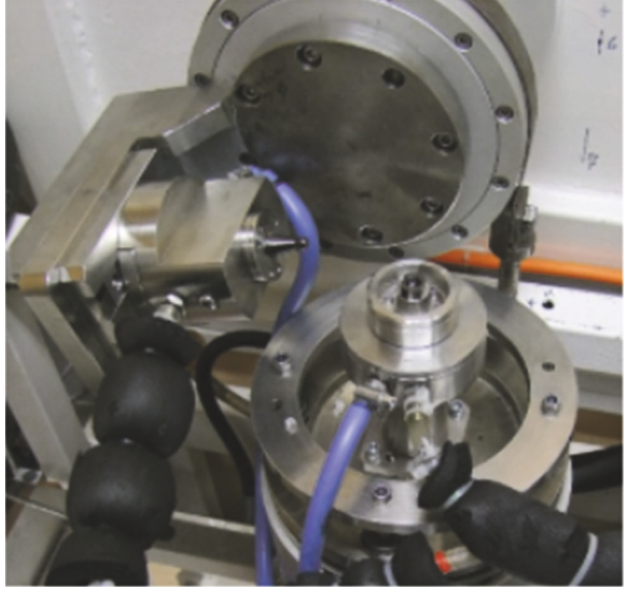

(a)

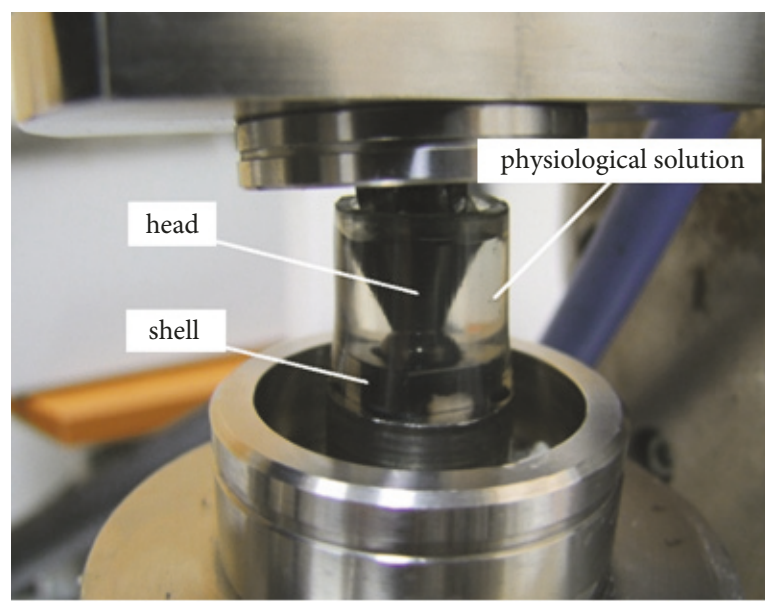

(b)

FIGURE 1: Finger joint wear simulator: (a) wear testing component arrangement; (b) test detail.

(PEEK) was calculated by FEM (Finite Element Method, program Abaqus) analysis. Furthermore, the contact pressure was monitored as a function of the position in the cup, from centre to edge, for three values of the coefficient of friction (0.1-0.3).

Sliding behaviour was investigated on a finger joint wear simulator (Figure 1). For this purpose, the modified Ti6Al4V head (IBAD $40 \mathrm{~nm}$ ) with a $10 \mathrm{~mm}$ diameter and a PEEK cup was used. The normal load of $100 \mathrm{~N}$ was applied during the test.

\section{Results and Discussion}

3.1. Chemical Composition. The results of the nitrogen depth distribution and elemental chemical composition of the surface area have been published in detail elsewhere [34]. The maximum concentration of nitrogen lies in the substrate matrix, overlaps partially with the mixing area nanolayer/substrate, and interferes with the carbon-based nanolayer. Minimal nitrogen enrichment of the carbon-based nanolayer was observed. High ion energy has caused nitrogen penetration through the nanolayer into the substrate. Nitrogen peak movement deeper into the specimen was observed with the increasing thickness of the nanolayer. Implanted nitrogen behind the carbon-based nanolayer penetrated the substrate in the modified projected range and modified longitudinal straggling, which causes an increase in the maximum nitrogen concentration from approx. $17.4 \pm$ 1.6 at $\%$ for specimens with a nanolayer $20 \mathrm{~nm}$ in thickness to approx. $18.9 \pm 1.9$ at $\%$ for specimens with a nanolayer $40 \mathrm{~nm}$ in thickness. Oxygen contamination below 20 at\% was detected in the narrow region on both the surface and nanolayer/substrate interface. The presence of oxygen on the nanolayer/substrate interface is likely caused by air exposure before the deposition process and by imperfect removal in the sputter cleaning.

3.2. Phase Composition. X-ray diffraction (XRD) method was used to determine the phase composition of the modified

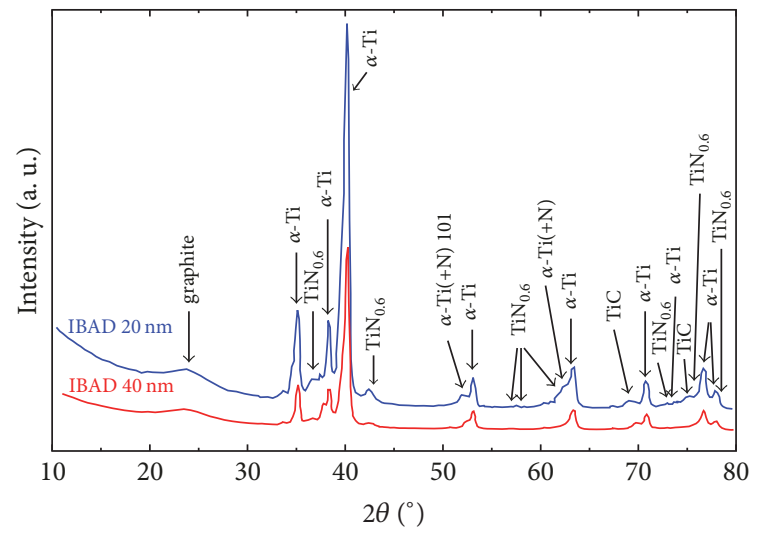

FIGURE 2: XRD spectra of modified specimens.

titanium alloy. Figure 2 shows XRD spectra of modified specimens IBAD $20 \mathrm{~nm}$ and IBAD $40 \mathrm{~nm}$. Nonstoichiometric $\mathrm{TiN}_{x}$ phases, $\mathrm{TiC}$, and graphite were detected in the surface area. The structural $\alpha$-phase of the Ti6Al4V alloy was confirmed, but no $\beta$-phase was found in the diffraction pattern. The structural $\alpha$-phase with incorporated nitrogen $\alpha-\operatorname{Ti}(+\mathrm{N})$ was found. The $\alpha-\operatorname{Ti}(+\mathrm{N})$ structural phase marks the hexagonal structure derived from the $\alpha$-Ti phase, but with enlarged lattice parameters due to incorporation of nitrogen in interstitial sites of the Ti matrix [31]. The uneven dispersion of implanted nitrogen with a near-Gaussian distribution [35] induces a $\mathrm{TiN}$ and $\mathrm{Ti}(+\mathrm{N})$ mixture formation in the implanted region [31].

Nitrogen concentration profiles [34] indicate that the observed $\operatorname{TiN}_{x}$ phase forms in the titanium matrix behind the carbon nanolayer. Results indicate the mixed area at the interface of carbon nanolayer and Ti6Al4V alloy due to ion bombardment. Formation of observed $\mathrm{TiC}$ compound is expected in this area. The new phases are located on the interface of titanium substrate/carbon-based nanolayer and the titanium sublayer. The results confirmed that the 


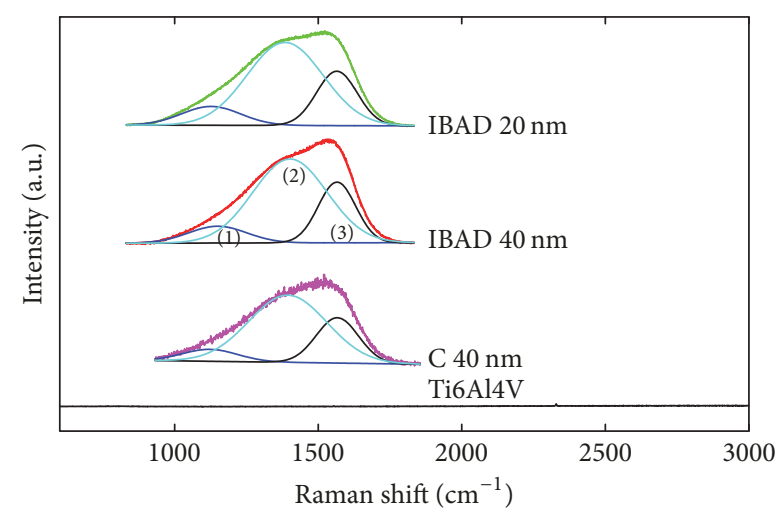

FIGURE 3: Raman spectra of carbon-based nanolayers prepared by nitrogen ion beam assisted deposition (IBAD $20 \mathrm{~nm}$; IBAD $40 \mathrm{~nm}$ ) and carbon-based nanolayer without nitrogen ion bombardment $(\mathrm{C}$ $40 \mathrm{~nm})$.

implanted nitrogen stabilizes the $\alpha$-phase of the Ti6Al4V alloy $[32,33]$.

3.3. Raman Spectroscopy. Qualitative changes of carbon bonding structure after ion implantation were analysed by Raman spectroscopy. Figure 3 shows Raman spectra of the carbon-based nanolayers deposited with assistance of nitrogen ions (IBAD $20 \mathrm{~nm}$, IBAD $40 \mathrm{~nm}$ ) and the spectrum of carbon nanolayer deposited without nitrogen ion bombardment $(\mathrm{C} 40 \mathrm{~nm})$. The peak parameters are stated in Table 2. Consistent fits are achieved using a combination of three peaks. Peak $1\left(1123-1150 \mathrm{~cm}^{-1}\right)$ has responded to nanocrystalline or amorphous diamond fraction [36]. Peak $2\left(1385-1402 \mathrm{~cm}^{-1}\right)$, known as a D peak, demonstrates the presence of disordered graphitic carbon, and peak 3 (1565-1567 $\left.\mathrm{cm}^{-1}\right)$, the so-called $\mathrm{G}$ peak, belongs to crystalline graphitic carbon occurring in the nanostructure [30,37]. The results show that ion bombardment during the deposition process increased peak intensity of Raman spectra for both thicknesses of carbon-based nanolayers. The ratio of the areas under the peaks increased due to nitrogen ion bombardment (Table 2). These results indicated that the high energy ion bombardment causes the graphitisation of carbon nanolayer for both applied thicknesses. According to Robertson's theory [38], ion bombardment helps to form the binding hybridization of amorphous carbon and related materials. The formation of $\mathrm{sp}^{2} / \mathrm{sp}^{3}$ binding hybridization is related to the local density produced by ion bombardment at various conditions. Many researchers have confirmed that ion bombardment at low energies (tens and hundreds of $\mathrm{eV}$ ) induces the formation of $\mathrm{sp}^{3}$ "diamond bonds" [39-41]. The high energy ion bombardment used here causes the accelerated nitrogen to penetrate into the titanium substrate. Part of this energy is dissipated in the atom displacements, and the rest of the energy is dissipated as phonons in due course [34]. Vlcak [29] demonstrated that $45 \mathrm{keV}$ nitrogen ion bombardment modified the carbon bonds in defect $\mathrm{sp}^{2}$ and defect $\mathrm{sp}^{3}$ hybridization, resulting in graphitisation of the carbon. The conversion of $\mathrm{sp}^{3}$ bonds to $\mathrm{sp}^{2}$ bonds with

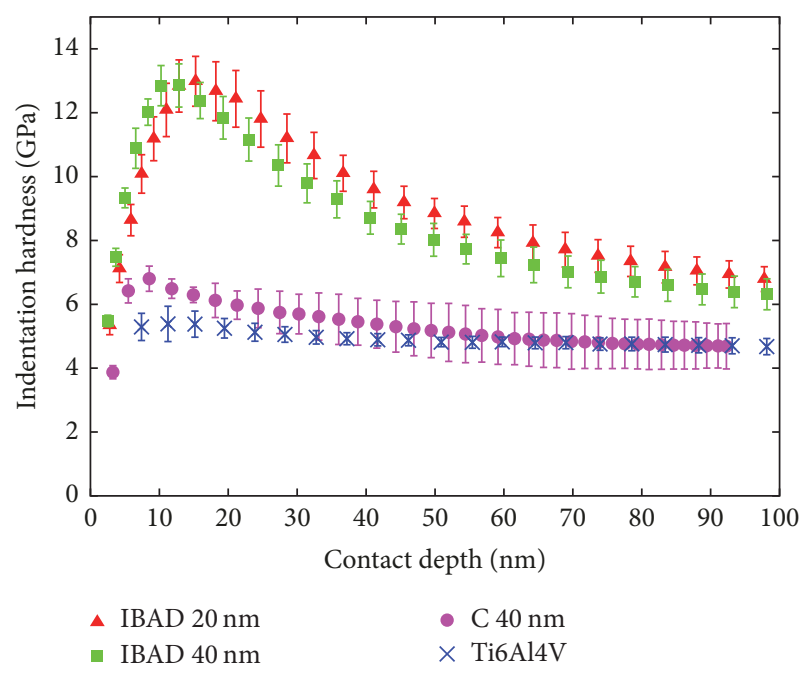

FIGURE 4: Depth profiles of the indentation hardness measurements.

increasing ion energy also confirmed Han et al. [42] and Wei et al. [43].

3.4. Surface Hardness. The resulting depth profiles of the indentation hardness are presented in Figure 4. The depth profile results of the control specimen (Ti6Al4V) show an almost constant trend in comparison with the coated specimens. The hardness increase $\left(\mathrm{H}_{\mathrm{IT}} 5.5 \pm 0.6 \mathrm{GPa}\right)$ in the near surface region of the control specimen is caused by strengthening after mechanical polishing. The specimens modified by carbon nanolayer without nitrogen ion assistance $(\mathrm{C} 40 \mathrm{~nm})$ have maximum hardness values $\mathrm{H}_{\mathrm{IT}} 6.8$ $\pm 0.4 \mathrm{GPa}$. The specimens with carbon-based nanolayers deposited with the assistance of nitrogen ions (IBAD $20 \mathrm{~nm}$, IBAD $40 \mathrm{~nm}$ ) have comparable values. The maximum hardness is close to $\mathrm{H}_{\text {IT }} 12.9 \pm 0.8 \mathrm{GPa}$ and $\mathrm{H}_{\text {IT }} 12.8 \pm 0.7 \mathrm{GPa}$ for specimens IBAD $20 \mathrm{~nm}$ and IBAD $40 \mathrm{~nm}$, respectively. Depth profiles are characterized by maximum values with a sharply decreasing trend approaching the hardness values of the control specimen. The influence of titanium alloy substrate is assumed near the interface with nanolayer. The nitrogen enrichment of titanium substrate together with the atomic mixing on the nanolayer/substrate interface led to the formation of hard $\mathrm{TiN}_{x}$ and $\mathrm{TiC}$ compounds. The presence of these phases detected by XRD causes specimen hardening with a graphitic nanolayer on top the surface $[18$, 22]. The results clearly show that specimen $C 40 \mathrm{~nm}$ has lower hardness in comparison with specimens IBAD $20 \mathrm{~nm}$ and IBAD $40 \mathrm{~nm}$. Relatively low hardness of amorphous carbon is well known [44]. The specimens coated with the carbon nanolayers deposited with nitrogen ion bombardment show a hardness increase due to substrate hardening (nitriding, formation of new hard $\mathrm{TiN}$ and $\mathrm{TiC}$ compounds). The Raman spectra show graphitisation of carbon nanolayers (degradation) after ion implantation (IBAD $20 \mathrm{~nm}$ and IBAD $40 \mathrm{~nm}$ ) which is in accordance with the literature $[29,38]$. However, formation of new compound in the titanium alloy surface causes hardening of the substrate at the same time. 
TABLE 2: The results of Raman spectra.

\begin{tabular}{|c|c|c|c|c|c|c|c|}
\hline \multirow[b]{3}{*}{ Layer type } & \multicolumn{6}{|c|}{ Peak no. } & \multirow[b]{3}{*}{$\begin{array}{c}\text { Ratio } \\
I(1+2) / I 3\end{array}$} \\
\hline & \multicolumn{2}{|r|}{1} & \multicolumn{2}{|r|}{2} & \multicolumn{2}{|c|}{3} & \\
\hline & $\begin{array}{l}\text { Peak position } \\
\quad\left(\mathrm{cm}^{-1}\right)\end{array}$ & $\begin{array}{l}\text { Intensity } \\
\text { (a.u.) }\end{array}$ & $\begin{array}{l}\text { Peak position } \\
\left(\mathrm{cm}^{-1}\right)\end{array}$ & $\begin{array}{l}\text { Intensity } \\
\text { (a.u.) }\end{array}$ & $\begin{array}{l}\text { Peak position } \\
\left(\mathrm{cm}^{-1}\right)\end{array}$ & $\begin{array}{l}\text { Intensity } \\
\text { (a.u.) }\end{array}$ & \\
\hline IBAD $20 \mathrm{~nm}$ & $1127 \pm 15$ & $(0.818 \pm 0.016) \mathrm{E} 6$ & $1385 \pm 16$ & $(4.653 \pm 0.044) \mathrm{E} 6$ & $1565 \pm 13$ & $(1.629 \pm 0.012) \mathrm{E} 6$ & 3.36 \\
\hline IBAD $40 \mathrm{~nm}$ & $1150 \pm 16$ & $(0.721 \pm 0.008) \mathrm{E} 6$ & $1402 \pm 19$ & $(4.577 \pm 0.009) \mathrm{E} 6$ & $1565 \pm 12$ & $(1.672 \pm 0.010) \mathrm{E} 6$ & 3.17 \\
\hline C $40 \mathrm{~nm}$ & $1123 \pm 11$ & $(0.539 \pm 0.006) \mathrm{E} 6$ & $1394 \pm 10$ & $(4.286 \pm 0.011) \mathrm{E} 6$ & $1567 \pm 18$ & $(1.564 \pm 0.009) \mathrm{E} 6$ & 3.09 \\
\hline
\end{tabular}

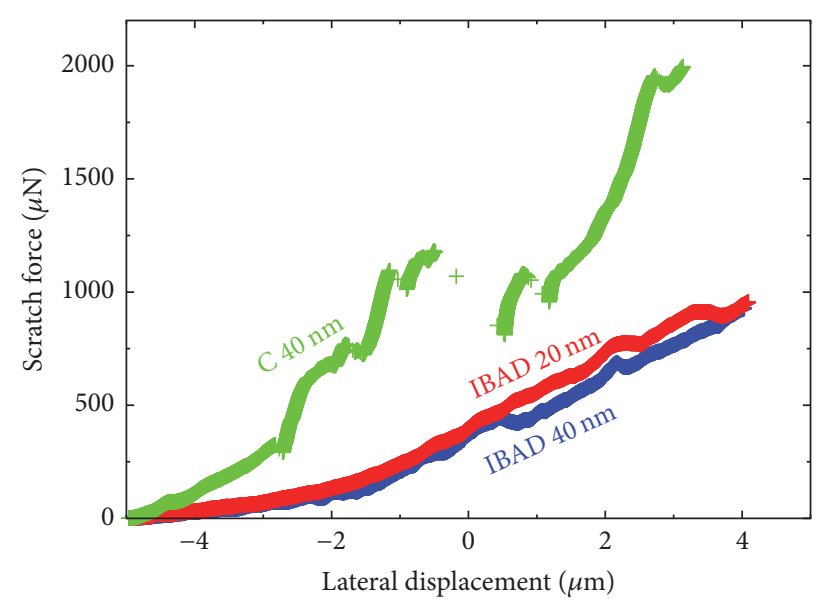

FIGURE 5: The trend of the scratch force according to the lateral displacement of the tip.

Thus specimens IBAD $20 \mathrm{~nm}$ and IBAD $40 \mathrm{~nm}$ show higher hardness in comparison with specimen C $40 \mathrm{~nm}$ which is consistent with other results. Presented results indicated that high energy ion bombardment causes graphitisation of carbon nanolayer (lubricating layer) and surface hardening of the substrate.

The comparable surface hardness of modified specimens IBAD $20 \mathrm{~nm}$ and IBAD $40 \mathrm{~nm}$ is given by applied fluence of implanted nitrogen. Applied fluence of implanted ions was 1 . $10^{17} \mathrm{~cm}^{-2}$ in both types of specimens (IBAD $20 \mathrm{~nm}$ and IBAD $40 \mathrm{~nm}$ ). Many researchers reported that surface hardness of nitrogen implanted titanium materials increases with increasing fluence $[16,33]$. Presented results confirm character of hardening which is the formation of new compounds in the substrate due to nitrogen incorporation. Specimen C $40 \mathrm{~nm}$ shows approximately comparable hardness with the substrate. Very low thickness of carbon-based nanolayer is on the detection limit of the nanoindentation method. Therefore, hardness profiles in Figure 4 mainly reflect the structural changes in the substrate.

3.5. Adhesion. The adhesion of carbon-based nanolayers to a substrate was investigated by nanoscratch testing. Figure 5 presents the typical trends of the scratch force according to the lateral displacement of the tip for the specimens coated by carbon-based nanolayers with ion bombardment (IBAD $20 \mathrm{~nm}$ and IBAD $40 \mathrm{~nm}$ ) and for the specimen coated by a

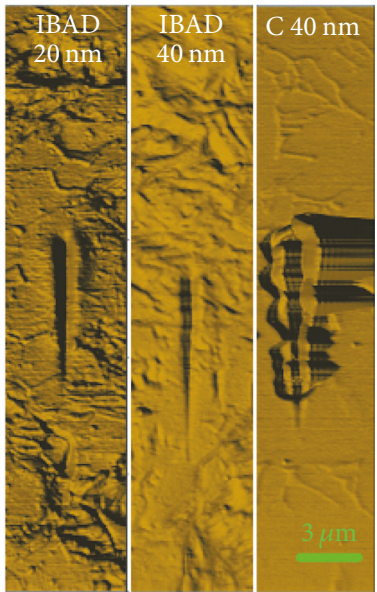

FIGURE 6: Images of specimen surface after nanoscratch test.

carbon nanolayer without ion bombardment (C $40 \mathrm{~nm})$. The scratch force increases with increasing lateral displacement. A comparison of the curves in Figure 5 shows that the scratch force for the same lateral displacement value is greater for specimen C $40 \mathrm{~nm}$. This indicates easier penetration of the tip into the material which is in agreement with the presented hardness results. The specimens coated by a carbon-based nanolayer with ion bombardment (IBAD $20 \mathrm{~nm}$ and IBAD $40 \mathrm{~nm}$ ) show similar trends. A comparable behaviour is given by a character of substrate hardening. A smooth course of the scratch force along the lateral displacement is observed on specimens coated by carbonbased nanolayers with ion bombardment, while the course of the scratch force on the specimen coated by a carbon nanolayer without ion assistance shows step decrease in the scratch force. The visible jumps (curve discontinuities) indicate delamination of the carbon nanolayer. It is confirmed by the scans of scratches of the tested specimens (Figure 6). The carbon-based nanolayers deposited with ion bombardment show no signs of delamination. It can be assumed that the ion bombardment improved the adhesion of the nanolayers.

3.6. Coefficient of Friction. Figure 7 shows the dependence of the coefficient of friction on the number of cycles for the coated specimens (IBAD $20 \mathrm{~nm}$, IBAD $40 \mathrm{~nm}$ ) and for the control substrate (Ti6Al4V). The lubrication effect of carbonbased nanolayer on Ti6Al4V alloy is demonstrated. The two 


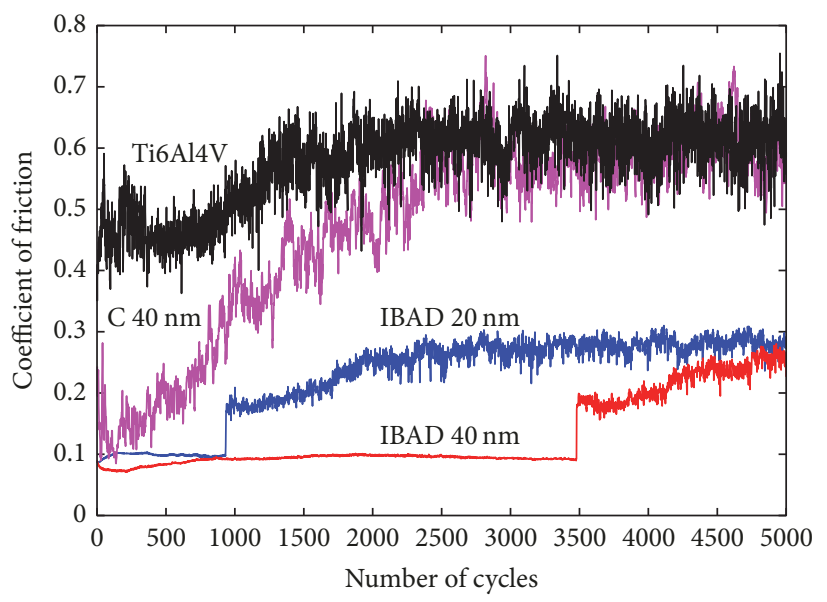

FIGURE 7: Coefficient of friction versus the number of cycles for modified specimens (IBAD $20 \mathrm{~nm}$, IBAD $40 \mathrm{~nm}$ ) in comparison with coated specimen without ion bombardment (C $40 \mathrm{~nm}$ ) and unmodified control specimen (Ti6Al4V).

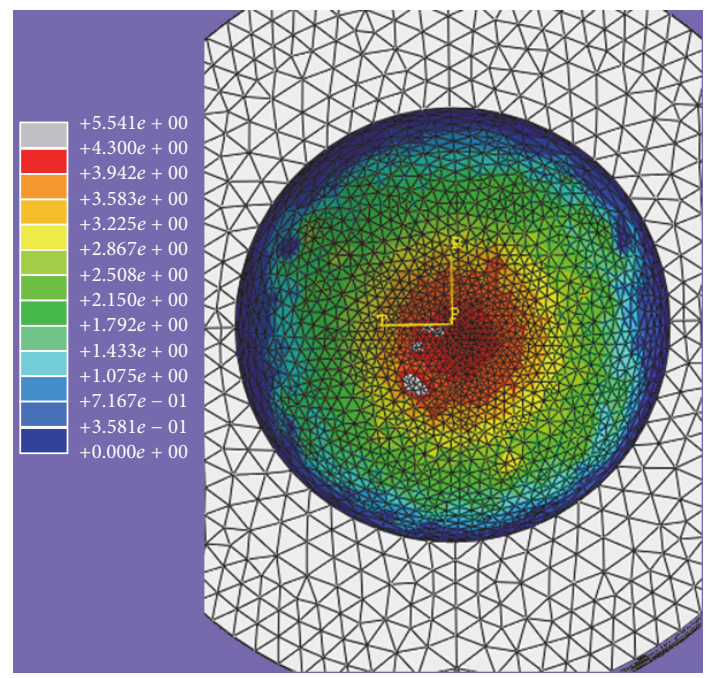

(a)

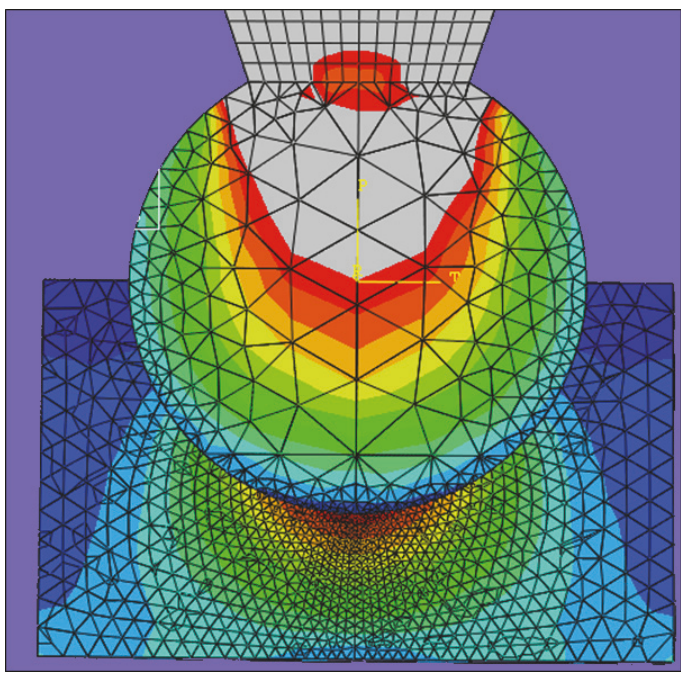

(b)

Figure 8: Contact pressure distribution between the PEEK cup (a) and Ti6Al4V head (b) simulated by FEM analysis using the Abaqus program.

surface modifications IBAD $40 \mathrm{~nm}$ and IBAD $20 \mathrm{~nm}$ have comparable coefficient of friction values of $0.106 \pm 0.003$ and $0.104 \pm 0.005$, respectively. Carbon-based nanolayers of both thicknesses show much lower coefficient of friction versus the coefficient of friction of $0.635 \pm 0.139$ for control Ti6Al4V substrate. A thicker nanolayer (IBAD $40 \mathrm{~nm}$ ) increased the duration of the lubrication effect by more than three times compared to a thinner nanolayer (IBAD $20 \mathrm{~nm}$ ). The achieved results are consistent with the results of other research works [22, 45]. Step increasing in the coefficient of friction implies the failure of the thin carbonbased nanolayer on specimens IBAD $20 \mathrm{~nm}$ and IBAD $40 \mathrm{~nm}$. However, the coefficient of friction does not reach the value of unmodified substrate as in the case of specimen C $40 \mathrm{~nm}$. Hardened substrate by nitrogen implantation poses friction resistant surface with low friction coefficient, typical for nitrogen ion implanted titanium materials. Gordin et al.
[46] observed on nitrogen implanted $\mathrm{Ti}-\mathrm{Nb}-\mathrm{Ta}$ titanium alloy comparable value of coefficient of friction of about 0.3 .

3.7. Contact Pressure Distribution and Joint Wear Simulation. The distribution of contact pressure was calculated by FEM analysis using the Abaqus program. Figure 8 shows a 3D model of the finger joint with contact pressure distribution (the head (Ti6Al4V) and the cup (PEEK)). The simulation was performed with load force $F=100 \mathrm{~N}$ and coefficient of friction $\mu=0.1$. The maximum contact pressure of about $4 \mathrm{MPa}$ was found in the deepest point of the cup under the ideal geometrical shape of the head and cup. Values vary from $0 \mathrm{MPa}$ (around the perimeter of the cup, contact angle of $90^{\circ}$ ) to $p_{\max } \sim 4 \mathrm{MPa}$ (at the deepest point of the cup). Figure 9 presents the evolution of contact pressure in the cup in dependence on the contact angle for different values of the 


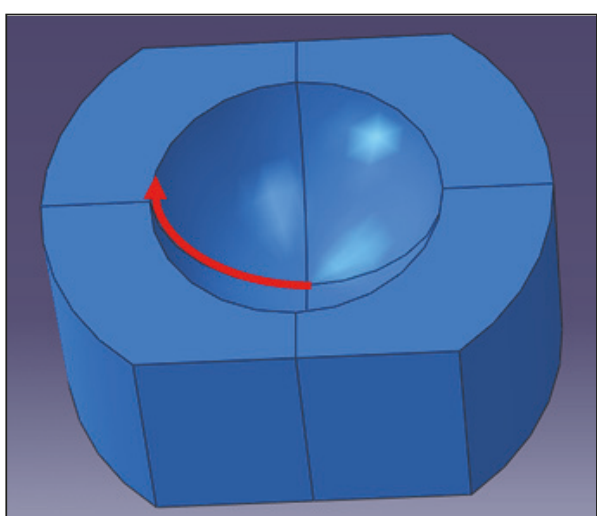

(a)

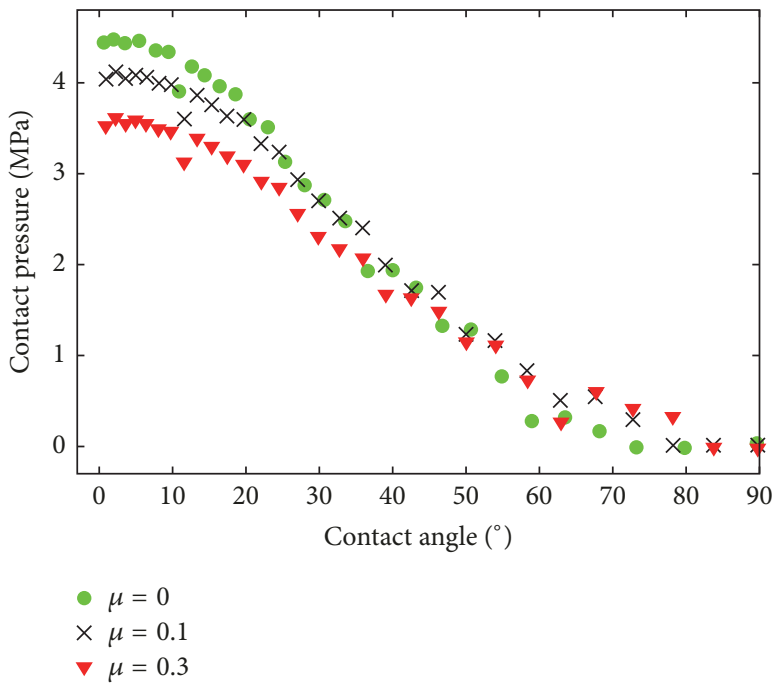

(b)

Figure 9: The calculated contact pressure distribution inside the cup of joint: (a) evaluated trajectory, red arrow; (b) the dependence of contact pressure on the contact angle for different value of coefficients of friction.
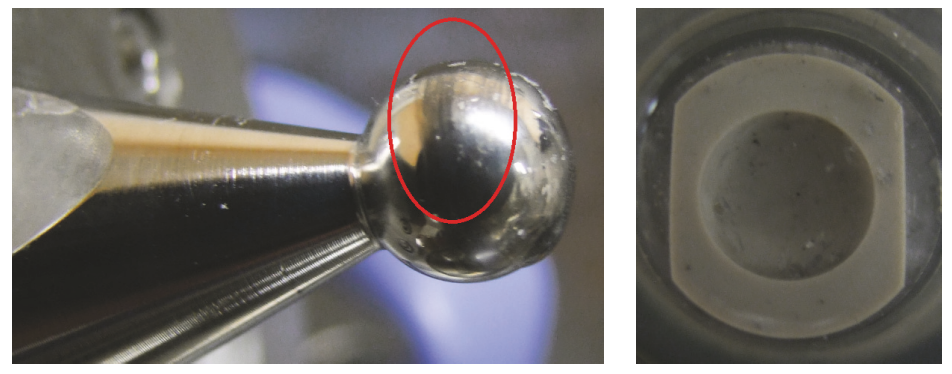

FIgUre 10: Unmodified Ti6Al4V head and the cup after 10,000 cycles.

coefficient of friction. It is evident that the friction coefficient values affect the course of the contact pressure. The contact pressure varies in dependence on coefficient of friction up to the contact angle of approx. $25^{\circ}$ (i.e., in the centre of the cup). Maximum contact pressure decreases with increasing coefficient of friction. Lower values of contact pressure, however, do not mean lower contact stress or transmission of less force. For the higher coefficient of friction, the force transmission is realised mainly through shear stresses instead of normal stresses.

The joint wear simulator (Figure 1) was used for wear evaluation of the Ti6Al4V alloy head modified by carbonbased nanolayer (IBAD $40 \mathrm{~nm}$ ). The experimental model of a finger joint replacement, the head from modified Ti6Al4V, and the cup from PEEK were used. The appearance of component surfaces tested by sliding test was evaluated qualitatively. The Ti6Al4V head without a modified surface was used as a control. Enormous wear of the head and cup after 10,000 cycles in comparison with the modified Ti6Al4V head is evident (Figure 10). The first wear signs of the IBAD $40 \mathrm{~nm}$ nanolayer were observed after 240,000 cycles and were detected only in a local area (Figure 11). More extensive wear occurred after 510,000 cycles.

\section{Conclusion}

The carbon-based nanolayer with nitrogen ion assistance was deposited by IBAD method on the Ti6Al4V substrate. The proposed surface treatment of the titanium alloy, in two thickness variants, leads to an improvement of tribomechanical properties. The formation of $\mathrm{TiN}_{x}$ and $\mathrm{TiC}$ compounds in the modified surface area was found. Nitrogen ion bombardment had a more positive effect on higher values of indentation hardness than the layer deposited without ion bombardment. The larger thickness of carbonbased nanolayer improves friction test duration, but no influence on surface hardness was observed. The proposed surface modification (IBAD $40 \mathrm{~nm}$ ) of the Ti6Al4V joint head provides functional surface protection with a resulting reduction in wear and significant increase in lifetime. This modification of the titanium surface is very promising for biomedical application, especially in an area of load-bearing joint replacements. 

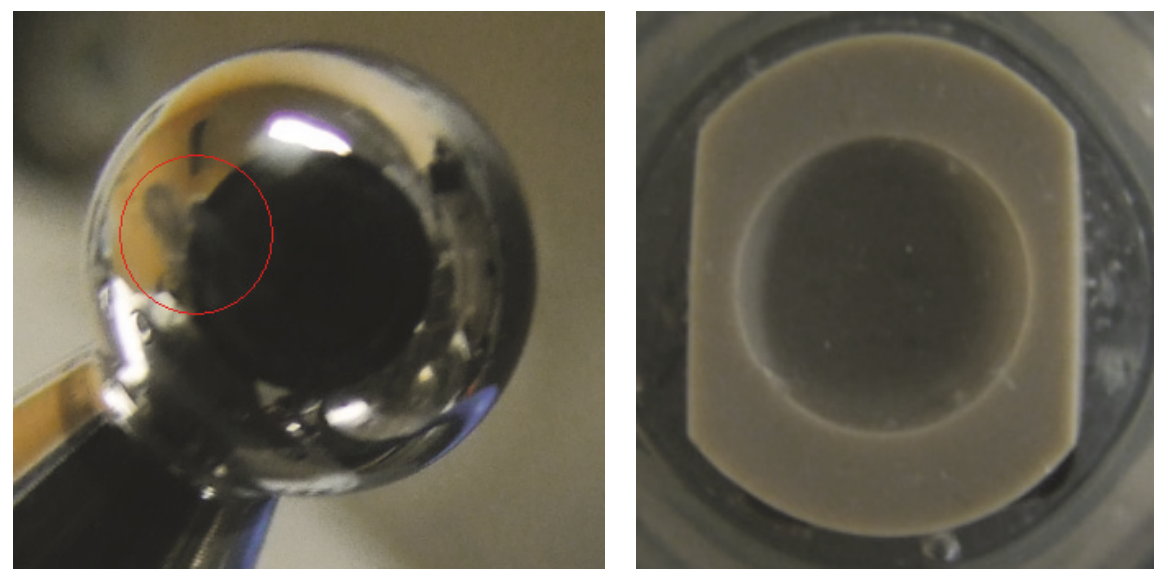

FIGURE 11: First local wear fault of the IBAD $40 \mathrm{~nm}$ modification after 240,000 cycles.

\section{Conflicts of Interest}

The authors declare that there are no conflicts of interest regarding the publication of this paper.

\section{Acknowledgments}

This research has been supported by the Ministry of Education, Youth and Sports of the Czech Republic Project SGS15/186/OHK2/3T/12, the Czech Technical University in Prague Project SGS18/173/OHK2/3T/12, and the Program PROGRES Q29 (Charles University, Czech Republic).

\section{References}

[1] J. Black and G. Hastings, Handbook of biomaterial properties, Chapman \& Hall, London, 1998.

[2] R. Godley, D. Starosvetsky, and I. Gotman, "Corrosion behavior of a low modulus $\beta-\mathrm{Ti}-45 \% \mathrm{Nb}$ alloy for use in medical implants," Journal of Materials Science: Materials in Medicine, vol. 17, no. 1, pp. 63-67, 2006.

[3] M. Jelínek, P. Vaněk, Z. Tolde et al., "PLD prepared bioactive BaTiO3 films on TiNb implants," Materials Science and Engineering C: Materials for Biological Applications, vol. 70, pp. 334339, 2017.

[4] R. Huiskes, H. Weinans, and B. Van Rietbergen, "The relationship between stress shielding and bone resorption around total hip stems and the effects of flexible materials," Clinical Orthopaedics and Related Research, vol. 274, pp. 124-134, 1992.

[5] B. Piotrowski, A. A. Baptista, E. Patoor, P. Bravetti, A. Eberhardt, and P. Laheurte, "Interaction of bone-dental implant with new ultra low modulus alloy using a numerical approach," Materials Science and Engineering C: Materials for Biological Applications, vol. 38, no. 1, pp. 151-160, 2014.

[6] C. C. Gomes, L. M. Moreira, V. J. S. V. Santos et al., "Assessment of the genetic risks of a metallic alloy used in medical implants," Genetics and Molecular Biology, vol. 34, no. 1, pp. 116-121, 2011.

[7] M. Geetha, A. K. Singh, R. Asokamani, and A. K. Gogia, "Ti based biomaterials, the ultimate choice for orthopaedic implants-a review," Progress in Materials Science, vol. 54, no. 3, pp. 397-425, 2009.
[8] M. Niinomi, Y. Liu, M. Nakai, H. Liu, and H. Li, "Biomedical titanium alloys with Young's moduli close to that of cortical bone," Regenerative Biomaterials, vol. 3, no. 3, pp. 173-185, 2016.

[9] I. V. Okulov, A. S. Volegov, H. Attar et al., "Composition optimization of low modulus and high-strength TiNb-based alloys for biomedical applications," Journal of the Mechanical Behavior of Biomedical Materials, vol. 65, pp. 866-871, 2017.

[10] M. Fischer, P. Laheurte, P. Acquier et al., "Synthesis and characterization of Ti-27.5Nb alloy made by CLAD ${ }^{\circledR}$ additive manufacturing process for biomedical applications," Materials Science and Engineering C: Materials for Biological Applications, vol. 75, pp. 341-348, 2017.

[11] A. Mishra, "Analysis of friction and wear of titanium alloys," in Proceedings of the International Journal of Mechanical Engineering and Robotics Research, vol. 3, pp. 570-573, 2014.

[12] S. Podzimek, M. Tomka, T. Nemeth, L. Himmlova, P. Matucha, and J. Prochazkova, "Influence of metals on cytokines production in connection with successful implantation therapy in dentistry," Neuroendocrinology Letters, vol. 31, no. 5, pp. 657$662,2010$.

[13] A. V. Lombardi Jr., T. H. Mallory, B. K. Vaughn, and P. Drouillard, "Aseptic loosening in total hip arthroplasty secondary to osteolysis induced by wear debris from titanium-alloy modular femoral heads," Journal of Bone and Joint Surgery-American Volume, vol. 71, no. 9, pp. 1337-1342, 1989.

[14] P. A. Lalor, P. A. Revell, A. B. Gray, S. Wright, G. T. Railton, and M. A. R. Freeman, "Sensitivity to titanium. A cause of implant failure?" The Journal of Bone \& Joint Surgery (British Volume), vol. 73, no. 1, pp. 25-28, 1991.

[15] K. Müller and E. Valentine-Thon, "Hypersensitivity to titanium: Clinical and laboratory evidence," Neuroendocrinology Letters, vol. 27, no. 1, pp. 31-35, 2006.

[16] A. Zhecheva, W. Sha, S. Malinov, and A. Long, "Enhancing the microstructure and properties of titanium alloys through nitriding and other surface engineering methods," Surface and Coatings Technology, vol. 200, no. 7, pp. 2192-2207, 2005.

[17] R. P. Van Hove, I. N. Sierevelt, B. J. Van Royen, and P. A. Nolte, "Titanium-Nitride Coating of Orthopaedic Implants: A Review of the Literature," BioMed Research International, vol. 2015, Article ID 485975, 2015.

[18] V. J. Trava-Airoldi, L. F. Bonetti, G. Capote, L. V. Santos, and E. J. Corat, "A comparison of DLC film properties obtained by r.f. 
PACVD, IBAD, and enhanced pulsed-DC PACVD," Surface and Coatings Technology, vol. 202, no. 3, pp. 549-554, 2007.

[19] J. P. Davim and F. Mata, "Chemical vapour deposition (CVD) diamond coated tools performance in machining of PEEK composites," Materials and Corrosion, vol. 29, no. 8, pp. 15681574, 2008.

[20] G.-G. Wang, H.-Y. Zhang, W.-Y. Li et al., "The preparation and evaluation of graded multilayer ta-C films deposited by FCVA method," Applied Surface Science, vol. 257, no. 11, pp. 5064-5069, 2011.

[21] S. A. Ahmad Kamal, R. Ritikos, and S. Abdul Rahman, "Wetting behaviour of carbon nitride nanostructures grown by plasma enhanced chemical vapour deposition technique," Applied Surface Science, vol. 328, pp. 146-153, 2015.

[22] P. Vlcak and I. Jirka, "Protective sliding carbon-based nanolayers prepared by argon or nitrogen ion-beam assisted deposition on Ti6Al4V alloy," Journal of Nanomaterials, vol. 2016, Article ID 1697090, 9 pages, 2016.

[23] H. Huang, X. Wang, and J. He, "Synthesis and properties of graphite-like carbon by ion beam-assisted deposition," Materials Letters, vol. 57, no. 22-23, pp. 3431-3436, 2003.

[24] P. Ren, E. Pu, D. Liu, Y. Wang, B. Xiang, and X. Ren, "Fabrication of nitrogen-doped graphenes by pulsed laser deposition and improved chemical enhancement for Raman spectroscopy," Materials Letters, vol. 204, pp. 65-68, 2017.

[25] R. J. Narayan, "Pulsed laser deposition of functionally gradient diamondlike carbon-metal nanocomposites," Diamond and Related Materials, vol. 14, no. 8, pp. 1319-1330, 2005.

[26] I. N. Mihailescu, D. Bociaga, G. Socol et al., "Fabrication of antimicrobial silver-doped carbon structures by combinatorial pulsed laser deposition," International Journal of Pharmaceutics, vol. 515, no. 1-2, pp. 592-606, 2016.

[27] D. F. Wang, K. Kato, and N. Umehara, "Mechanical characterization and tribological evaluation of ion-beam-assisted sputter coatings of carbon with nitrogen incorporation," Surface and Coatings Technology, vol. 123, no. 2-3, pp. 177-184, 2000.

[28] P. Vlcak, F. Cerny, Z. Weiss et al., "The effect of nitrogen ion implantation on the surface properties of Ti6Al4V alloy coated by a carbon nanolayer," Journal of Nanomaterials, vol. 2013, Article ID 475758, 8 pages, 2013.

[29] P. Vlcak, "The effect of ion irradiation and elevated temperature on the microstructure and the properties of $\mathrm{C} / \mathrm{W} / \mathrm{C} / \mathrm{B}$ multilayer coating," Applied Surface Science, vol. 365, pp. 306-313, 2016.

[30] P. Vlcak, J. Sepitka, T. Horazdovsky, I. Jirka, I. Gregora, and M. Nemec, "Nanomechanical testing of an a-C:N nanolayer prepared by ion beam assisted deposition on Ti6Al4V alloy," in Proceedings of the 7th International Conference on Nanomaterials - Research and Application, NANOCON 2015, pp. 68-72, cze, October 2015.

[31] P. Vlcak, J. Drahokoupil, P. Vertat, J. Sepitka, and J. Duchon, "Hardness response to the stability of a $\mathrm{Ti}(+\mathrm{N})$ solid solution in an annealed $\mathrm{TiN} / \mathrm{Ti}(+\mathrm{N}) / \mathrm{Ti}$ mixture layer formed by nitrogen ion implantation into titanium," Journal of Alloys and Compounds, vol. 746, pp. 490-495, 2018.

[32] H. Schmidt, A. Schminke, M. Schmiedgen, and B. Baretzky, "Compound formation and abrasion resistance of ionimplanted Ti6Al4V," Acta Materialia, vol. 49, no. 3, pp. 487-495, 2001.

[33] P. Vlcak, F. Cerny, J. Drahokoupil, J. Sepitka, and Z. Tolde, "The microstructure and surface hardness of Ti6Al4V alloy implanted with nitrogen ions at an elevated temperature," Journal of Alloys and Compounds, vol. 620, pp. 48-54, 2015.

[34] P. Vlcak, T. Horazdovsky, R. Valenta, and J. Kovac, "Evolution of the nitrogen depth distribution in an implanted titanium alloy with a surface carbon nanolayer," Chemical Physics Letters, vol. 679, pp. 25-30, 2017.

[35] Z. Weiss and P. Vlcak, "Analysis of shallow depth profiles of titanium nitride and $\mathrm{N}$-implanted titanium by GD-OES: The 'hydrogen effect' after the discharge startup and a correction thereof," Journal of Analytical Atomic Spectrometry, vol. 32, no. 12, pp. 2476-2484, 2017.

[36] M. M. Morshed, B. P. McNamara, D. C. Cameron, and M. S. J. Hashmi, "Stress and adhesion in DLC coatings on 316L stainless steel deposited by a neutral beam source," Journal of Materials Processing Technology, vol. 143-144, no. 1, pp. 922-926, 2003.

[37] Y. Funada, K. Awazu, K. Shimamura, and M. Iwaki, "Thermal properties of DLC thin films bombarded with ion beams," Surface and Coatings Technology, vol. 103-104, pp. 389-394, 1998.

[38] J. Robertson, "Diamond-like amorphous carbon," Materials Science and Engineering: R: Reports, vol. 37, pp. 129-282, 2002.

[39] J. Robertson, "Deposition mechanisms for promoting sp3 bonding in diamond-like carbon," Diamond and Related Materials, vol. 2, no. 5-7, pp. 984-989, 1993.

[40] P. A. Karaseov, O. A. Podsvirov, A. I. Titov et al., "Effect of ion bombardment on the phase composition and mechanical properties of diamond-like carbon films," Journal of Surface Investigation. X-ray, Synchrotron and Neutron Techniques, vol. 8, no. 1, pp. 45-49, 2014.

[41] P. Písařík, M. Jelínek, T. Kocourek et al., "Influence of diamond and graphite bonds on mechanical properties of DLC thin films," Journal of Physics: Conference Series, vol. 594, no. 1, Article ID 012008, 2015.

[42] L. Han, D. Liu, X. Chen, L. Yang, and Y. Zhao, “The deposition of a thick tetrahedral amorphous carbon film by argon ion bombardment," Applied Surface Science, vol. 258, no. 10, pp. 4794-4800, 2012.

[43] S. Wei, T. Shao, and J. Xu, "Effect of bombarding energy of $\mathrm{N}$ ions on composition, hardness and surface free energy of carbon nitride films," Surface and Coatings Technology, vol. 206, no. 19-20, pp. 3944-3948, 2012.

[44] S. Neuville and A. Matthews, "A perspective on the optimisation of hard carbon and related coatings for engineering applications," Thin Solid Films, vol. 515, no. 17, pp. 6619-6653, 2007.

[45] G. Popescu-Pelin, D. Craciun, G. Socol et al., "Investigations of pulsed laser deposited tin thin films for titanium implants," Romanian Reports in Physics, vol. 67, no. 4, pp. 1491-1502, 2015.

[46] D. M. Gordin, D. Busardo, A. Cimpean et al., "Design of a nitrogen-implanted titanium-based superelastic alloy with optimized properties for biomedical applications," Materials Science and Engineering C: Materials for Biological Applications, vol. 33, no. 7, pp. 4173-4182, 2013. 


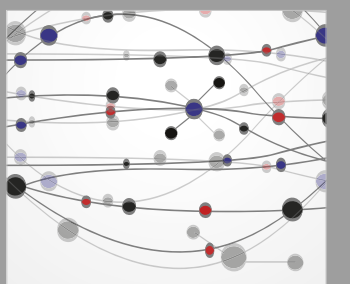

The Scientific World Journal
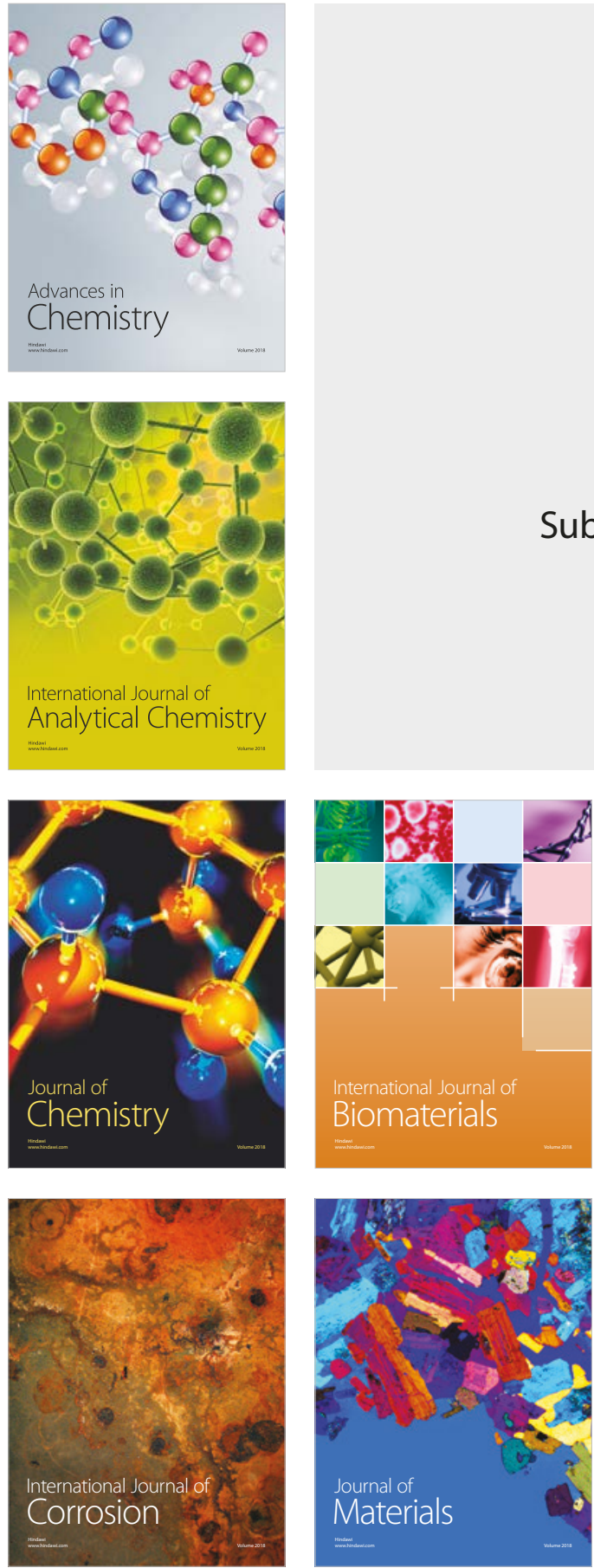

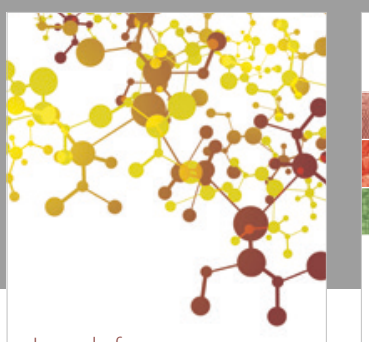

Journal of

Applied Chemistry
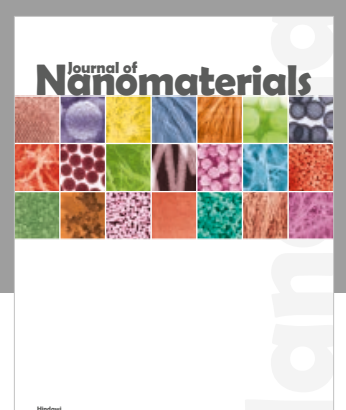

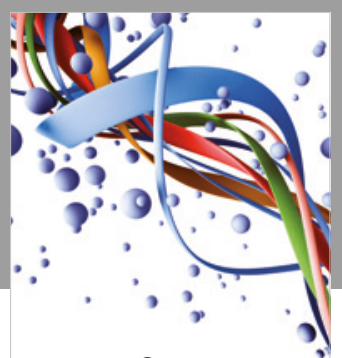

Scientifica

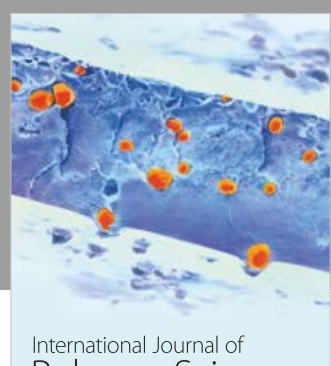

Polymer Science

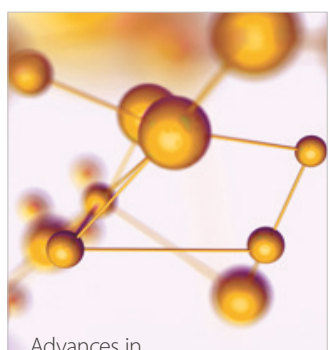

Physical Chemistry
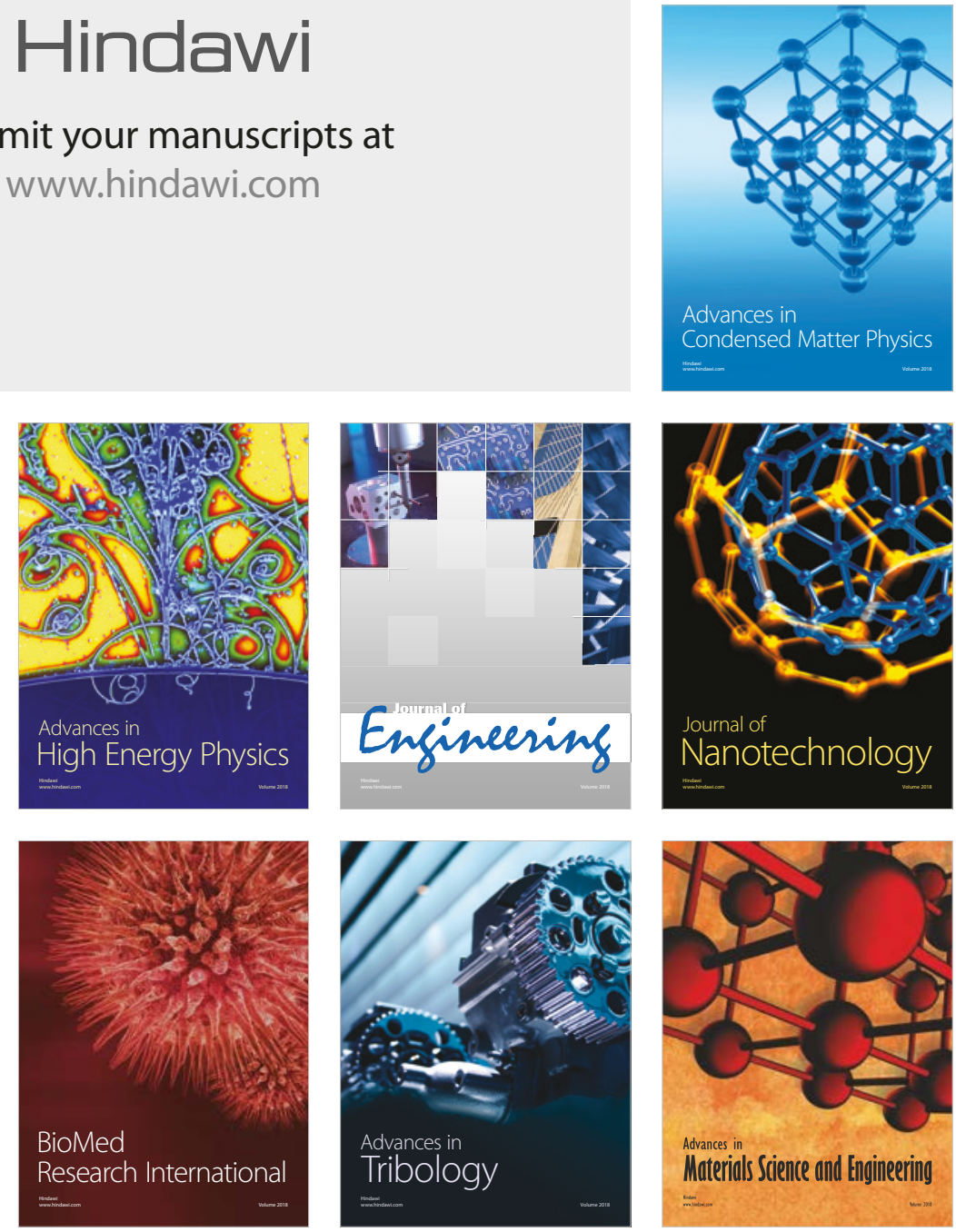